\title{
Comparison study of the influence of carbon and halloysite nanotubes on the preparation and rheological behavior of linear low density polyethylene
}

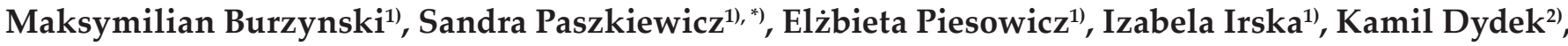 \\ Anna Boczkowska ${ }^{2)}$, Stanisław Wysocki ${ }^{3)}$, Jakub Sieminski ${ }^{1,3)}$
}

DOI: dx.doi.org/10.14314/polimery.2020.2.2

\begin{abstract}
Two 1D-types' nanofillers, in the form of multi-walled carbon nanotubes (MWCNTs) and halloysite nanotubes (HNTs), were introduced in an amount of 10, 15 and $20 \mathrm{wt} \%$ to linear low density polyethylene (LLDPE) in order to compare their effect on rheological properties. The neat LLDPE and its nanocomposites were obtained by direct melt blending. Since rheological properties have a key impact on the processing of polymer materials, it has been determined whether and how carbon and non-carbon nanotubes affect the viscosity of the composition. It was found that the addition of MWCNTs more significantly affects both the melt viscosity as well as the storage and loss moduli of the LLDPE matrix, compared to HNTs-based nanocomposites.
\end{abstract}

Keywords: carbon nanotubes, halloysite nanotubes, polyethylene, rheological properties, processing properties.

\section{Wpływ dodatku nanorurek węglowych oraz nanorurek haloizytowych na otrzymywanie i charakterystyki reologiczne liniowego polietylenu małej gęstości}

Streszczenie: Dwa rodzaje nanonapełniaczy 1D, w postaci wielościennych nanorurek węglowych (MWCNTs) oraz nanorurek haloizytowych (HNTs) wprowadzono do liniowego polietylenu małej gęstości (LLDPE) w ilości 10, 15 lub 20\% mas. Nienapełniony LLDPE oraz nanokompozyty na jego osnowie otrzymano metodą bezpośredniego mieszania w stanie stopionym. Zbadano wpływ dodatku nanonapełniaczy na właściwości reologiczne wytworzonych kompozytów determinujące ich przetwórstwo. Stwierdzono, że dodatek MWCNTs do polietylenowej osnowy znacznie wyraźniej niż dodatek HNTs wpływa zarówno na zwiększenie lepkości stopu, jak i na moduły: zachowawczy oraz stratności.

Słowa kluczowe: nanorurki węglowe, nanorurki haloizytowe, polietylen, właściwości reologiczne, właściwości przetwórcze.

Polyolefins are polymeric hydrocarbons consisting of two basic components, namely: hydrogen and carbon, which are further organized into long chains [1]. These materials belong to the greatly popular wide group of plastics materials (synthetic materials) due to their unique properties such as low density, good chemical resistance, low moisture absorption, very good chemical resistance,

\footnotetext{
1) West Pomeranian University of Technology, Institute of Material Science and Engineering, al. Piastów 19, 70-310 Szczecin, Poland.

2) Warsaw University of Technology, Faculty of Materials Science and Engineering, Woloska 141, 05-507 Warszawa, Poland. 3) TELE-FONIKA Kable S.A., H. Cegielskiego 1, 32-400 Myślenice, Poland.

*) Author for correspondence; e-mail: spaszkiewicz@zut.edu.pl
}

resistance to corrosion and good electrical insulation [1]. They are applied in many industrial fields, especially in the cable industry, electrochemical, electromechanical, for the production of food films, agricultural films, garden furniture, containers for yogurt, packaging for sweets, for the production of pipes, household appliances and many parts in the automotive industry [2]. Typically, natural gas or crude oil are two main resources used for their large scale production. The most commonly known representative of the polyolefin group is polyethylene (PE) [1]. Six grades of polyethylene can be distinguished, low density polyethylene (LDPE), high density polyethylene (HDPE), medium density polyethylene (MDPE), linear low density polyethylene (LLDPE), ultra-high-molecular-weight polyethylene (UHMWPE), cross-linked PE (XLPE).

Polyethylene is a widely applied polymer due to its outstanding properties like: low coefficient of friction, good 
self-lubricating properties, high resistance to abrasion and wear, high mechanical resistance, high resistance to aggressive substances (solutions of salts, acids, alkalis, alcohols and gasoline), low solubility in organic solvents below $60^{\circ} \mathrm{C}$, high dimensional stability, ability to noise reduction, good insulating properties, low moisture absorption, allowed to come into contact with food (PZH certificate) [1]. Despite to above mentioned advantages, PE exhibits also a number of serious drawbacks. Therefore, it is crucial to improve its flexibility while maintaining strength, improving fracture toughness with high stiffness, improving mechanical properties, increasing the flow and ignition temperature, lowering thermal expansion and increasing creep resistance. In order to eliminate PE's "bottlenecks", various strategies leading to the improvement of barrier, mechanical and thermal properties were studied, including PE blending with other polymers: polyamide (PA), acrylonitrile/butadiene/styrene (ABS), polystyrene (PS), poly(ethylene terephthalate) (PET), polypropylene (PP), poly(vinyl chloride) PVC, poly(methyl methacrylate) (PMMA), ethylene-vinyl acetate (EVA) [3] or the addition of nanofillers for instance: carbon nanotubes (CNTs), montmorillonite (MMT), polyhedral oligomeric silsesquioxane (POSS) [4].

Currently, the particular interest of researchers aroused mineral nanoparticles, especially in the cable industry, where mineral nanofillers are introduced to PE based materials [5]. The displayed modified composites have improved mechanical properties [5]. The beneficial effect of halloysite nanotubes (HNTs) on the improvement of properties in relation to materials without nanofillers, caused a growing interest in the use of the HNTs. The HNTs' morphology is similar to multi-layer carbon nanotubes [6, 7]. HNTs contain hydroxyl groups, which allows further modification with organic compounds. Moreover, HNTs are environmental amicable, naturally occurring and cheap. They also have unique tubular nanostructure and high aspect ratio, because they may replacement of carbon nanotubes, which production process is highly expensive [7]. The modulus of elasticity of HNTs is 140 GPa (with theoretical values of 230$340 \mathrm{GPa})[7,8]$. The density of HNTs are relatively low $\left(2.14-2.59 \mathrm{~g} / \mathrm{cm}^{3}\right)$ in comparison with other mineral fillers, which is a very important characteristic for light-weight polymer composites applications [8, 9]. HNTs have been found in soils all over the world, and the large deposit is also in Poland [10]. The stone-like, raw halloysite is easily ground into powder form. From the industrial point of view, the most important issue is the relatively low price of HNTs (1 kg = 431.64 \$ [11]) in comparison to carbon nanotubes $(1 \mathrm{~kg}=37600.20$ \$ [12]). Therefore, HNTs may be an interesting alternative with significant potential to commercialization, especially in the application, which requires materials cost reduction. HNTs are used for the production of high quality porcelain, in the ceramic and cement industries as well as fertilizer products [13, 14]. Both carbon nanotubes and HNTs have unique chemical, mechanical, electrical and magnetic properties.
The mixing of polyolefins such as LDPE with nanofillers can significantly improve the properties of polymers $[15,16]$. Furthermore, the features of a modified polymer can be tunable through the addition of a suitable amount and type of nanofillers in dependence on their future application. However, the adjustment of appropriate parameters requires further investigation.

The aim of this study was the preparation of composites based on LLDPE and various nanofillers such as multi-walled carbon nanotubes (MWCNTs) and halloysite nanotubes (HNTs). The rheological properties of obtained materials were investigated and compared in great details.

\section{EXPERIMENTAL PART}

\section{Materials}

- Linear low density polyethylene (LLDPE) (ExxonMobil F125W/855 58131) was used as a polymer matrix in the obtained nanocomposites, with a melt flow index (MFR $190^{\circ} \mathrm{C} / 2.16 \mathrm{~kg}$ ) $0.32 \mathrm{~g} / 10 \mathrm{~min}$. This material is widely used in the cable industry.

As nanofillers one used:

- halloysite nanotubes (HNTs) provided from Intermark, Gliwice (Poland) with the following characteristics: bulk density of 450-600 g/ $\mathrm{dm}^{3}$, color: grey-rusty red, ph: 6-7.5 (according to provider's data);

- thin multi-walled carbon nanotubes (MWCNTs, Nanocyl ${ }^{\circledR}$ NC7000 ${ }^{\mathrm{TM}}$ (Belgium) produced via the Catalytic Chemical Vapor Deposition (CCVD) process, with an average diameter of $9.5 \mathrm{~nm}$; average length of $1.5 \mu \mathrm{m}$; purity of $95 \%$; surface area of $250-300 \mathrm{~m}^{2} / \mathrm{g}$; volume resistivity of $10^{-4} \Omega \cdot \mathrm{cm}$.

\section{Preparation of LLDPE/HNTs and LLDPE/CNTs nanocomposites}

The series of materials, i.e. nanocomposites based on LLDPE containing 10, 15 and $20 \mathrm{wt}$.\% of HNTs/MWCNTs, were prepared on a counter-rotating twin screw extruder (LSM30, Leistritz Laborextruder) with tightly occurring coils and exchangeable mixing sections, (diameter: $D=34 \mathrm{~mm}$, ratio: $L / D=23$ ). Dosing of substrates took place from Brabender DDW-MD2-DDSR20-10 gravimetric feeders. The amount of dosing of individual substrates (loose and granular) was set according to the level of material extrusion at a speed of $1.8 \mathrm{~kg} / \mathrm{h}$. The following extrusion parameters were used: supply zone $-50{ }^{\circ} \mathrm{C}$, zone $1-70{ }^{\circ} \mathrm{C}$, zone $2-80^{\circ} \mathrm{C}$, zone $3-140^{\circ} \mathrm{C}$, zone $4-155^{\circ} \mathrm{C}$, zone $5-155^{\circ} \mathrm{C}$, zone $6-160{ }^{\circ} \mathrm{C}$, zone $7-170{ }^{\circ} \mathrm{C}$ and the screw rotation speed $-50 \mathrm{rpm}$.

\section{Methods of testing}

Samples for rheological analysis were prepared by the thermo-pressing process into discs with a thickness of 
$1 \mathrm{~mm}$ and a diameter of $25 \mathrm{~mm}$ directly from the pellets. A dynamic oscillatory stress-controlled rotational test was made in a parallel plate geometry mode using ARES rheometer (Rheometric Scientific Inc., TA Instruments, USA). The test was carried out at $150{ }^{\circ} \mathrm{C}$, from $0.1-100 \mathrm{~Hz}$ and with $1 \%$ of strain in order to observe how complex viscosity, storage $\left(G^{\prime}\right)$ and loss $\left(G^{\prime \prime}\right)$ modules change after addition multi-walled carbon nanotubes and halloysite nanotubes to LLDPE.

\section{RESULTS AND DISCUSSION}

The highly important issue allowing to understand polymer composites processability and structure property dependency is the investigation of their rheological behavior in melt state $[16,17]$. Melt rheological tests enable to evaluate the behavior of a large amount of material which is a crucial factor for precise macroscopic characterization. Moreover, the study of the viscoelastic properties of CNTs/HNTs/polymer composites has both practical importance related to composite processing and scientific importance as a probe of the composite dynamics and microstructure [18]. The rheological properties of nanotubes/polymer nanocomposites depend on several major factors such as structure and molecular weight of polymer matrix, type, loading and dispersion of the filler as well as the interfacial interaction between the polymer and filler [19]. The two commonly used techniques to characterize the rheological properties of CNTs/HNTs/ polymer composites is storage modulus and variations of viscosity as the function of frequency. The dependence between complex viscosity and frequency for neat and modified LLDPE is shown in Fig. 1.

The character of all curves is typical for non-Newtonian fluids. For all tested materials, the complex viscosity decreases as the frequency increases. Neat LLDPE was characterized by the lowest complex viscosity, while the highest complex viscosity was observed for the CNTsmodified materials and this viscosity increased as the CNTs content increased. LLDPE with HNTs was characterized by lower viscosity than those with CNTs and in comparison to neat LLDPE, the highest increase was observed for 15 and $20 \mathrm{wt} \%$, for which the viscosity was at a similar level.

To describe the elastic and viscous properties of characterized materials, the storage $\left(G^{\prime}\right)$ and loss $\left(G^{\prime \prime}\right)$ modules were analyzed, which was presented in Fig. 2 and Fig. 3.

In both cases, an increase was observed for the modified materials with applied frequency and for the highest frequency, a slight decrease was observed. The smallest values of storage and loss modulus were measured for neat LLDPE. LLDPE with CNTs was characterized by higher module values and the impact of frequency on the change of these values is smaller than LLDPE with HNTs. Comparing the two charts, it could be seen that the storage module achieves higher values than loss one for the corresponding materials, which means that these materials behave more like an elastic liquid when processed. These observations are in the agreement with Sandleret et al. [20] who observed that with an increasing concentration of carbon nanotubes the viscosity of the polymer system drastically changed above a certain value. Moreover, in our case, one can assume that the addition of nanofillers causes stiffening effect (Fig. 1). CNTs have a stronger

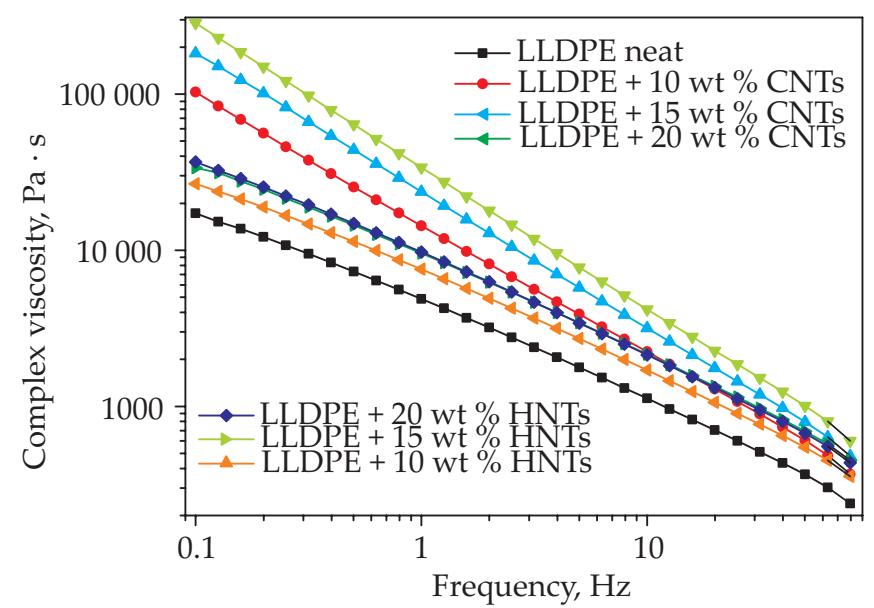

Fig. 1. Complex viscosity of the characterized materials

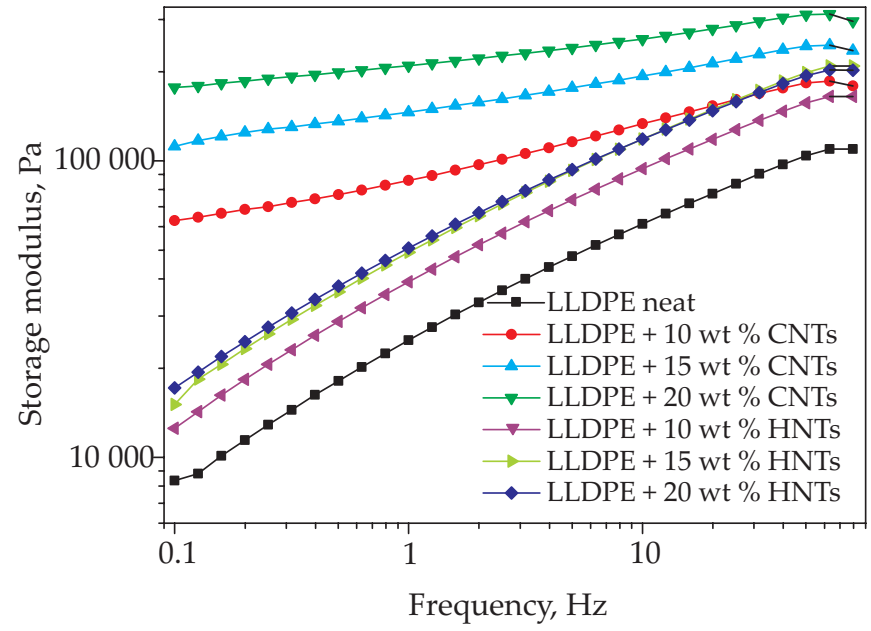

Fig. 2. The storage modulus of the characterized materials

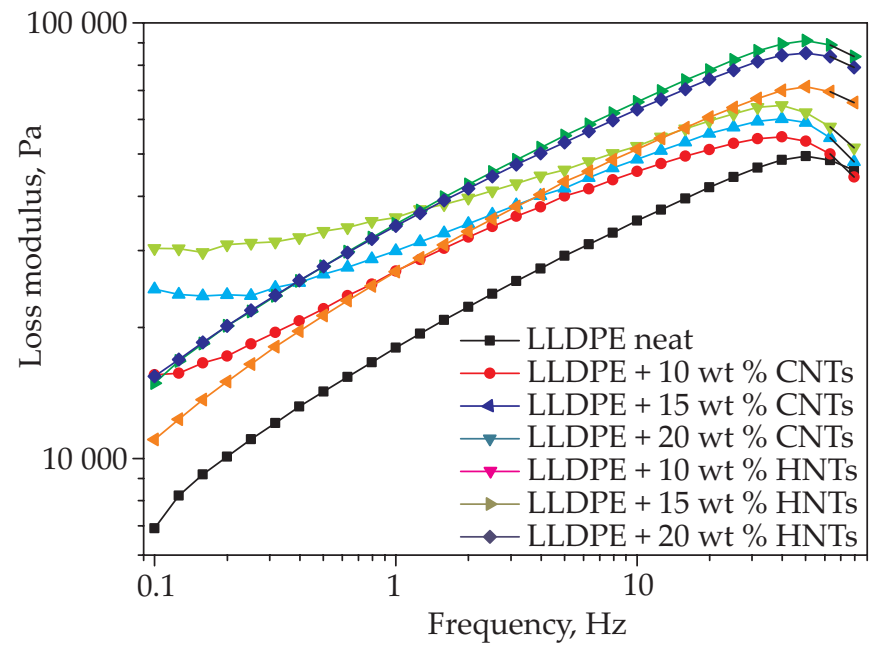

Fig. 3. The loss modulus of the characterized materials 
effect on LLDPE compared to HNTs. The incorporation of $15 \mathrm{wt} \%$ and $20 \mathrm{wt} \%$ of HNTs has a similar effect on the LLDPE rheological properties (curves overlap one another). In turn, the same amount of CNTs, i.e. $15 \mathrm{wt} \%$, caused an increase in complex viscosity in low frequencies $(0.1 \mathrm{~Hz})$ of over 10 times compared to neat LLDPE and 5 times compared to LLDPE $+15 \mathrm{wt} \%$ HNTs. Further increase in the concentration of CNTs results in an exponential increase in viscosity. Thus, one can assume that rheological analysis favors HNTs, as the nanofiller to LLDPE, relatively to carbon nanotubes. Moreover, the use of HNTs also improves the mechanical properties of the final composite [21]. In addition, in another polyolefin, i.e. PP, Huang et al. [22], observed that a better HNTs' dispersion in the PP matrix (SEM analysis) resulted in a higher value of storage modulus and complex viscosity at low frequencies. Furthermore, they observed, that despite no observation of plateau of $G^{\prime}$ at low frequencies, the rheological behavior of PP-based composites with low content of HNTs was greatly improved [22].

\section{CONCLUSIONS}

The aim of the study was to compare how organic (MWCNTs) and inorganic nanotubes (HNTs) affect rheological behavior and hence the processing properties of LLDPE. The conducted research has shown that MWCNTs has a greater effect on the melt viscosity, storage and loss moduli compared to composites containing HNTs. The addition of the nanofiller, which even at high content (like 15 or $20 \mathrm{wt} \%$ ) doesn't worse the processing properties, by means of drastic increase in viscosity, and which at the same time is much cheaper than MWCNTs, is more reasonable from the point of view of their applications in polymer technologies, including welding technology.

This work has been financed by TELE-FONIKA Kable S.A. within the project POIR.01.01.01-00-0148/17 granted by the resources of the National Centre for Research and Development in Warsaw, Poland under Operational Program Intelligent Development.

\section{REFERENCES}

[1] "Handbook of Polyolefins" (Ed. Vasile C.), CRC Press, Boca Raton 2000.

[2] Lohse D.J: "Polyolefins" in "Applied Polymer Science21st Century" (Eds. Craver C., Carraher C.), Elsevier, Amsterdam 2000, Chapter 6, pp. 73-91.

[3] Wypych G.: "Handbook of Polymers", ChemTec Publishing, Toronto 2016.

[4] Wang Y.: "Novel Fire Retardant Polymers and Composite Materials" (Ed. Wang D-Y.) Woodhead Publishing, 2017.
[5] Wang Y., Zhen L., Chang-Hong L.: "The Application of Plastic Modification Technology in Electric Wire and Cable Materials QIN", College of Polymer Science and Engineering, Sichuan University, Chengdu, China 2010.

[6] Szpilska K., Czaja K., Kudła S.: Polimery 2015, 60, 359. https://doi.org/10.14314/polimery.2015.359

[7] Esawi A.M.K., Morsi K., Sayed A. et al.: Composites Part A: Applied Science and Manufacturing 2011, 42, 234.

[8] Rooj S., Das A., Heinrich G.: European Polymer Journal 2011, 47, 1745.

[9] Ng K.M., Lau Y.T.R., Chan Ch.M. et al.: Surface and Interface Analysis 2011, 43, 795.

http://dx.doi.org/10.1002/sia.3627

[10] Sakiewicz P., Nowosielski R., Pilarczyk W. et al.: Journal of Achievements in Materials and Manufacturing Engineering 2011, 48, 177.

[11] https://www.sigmaaldrich.com access on 11.06.2019.

[12] https://www.nanocyl.com/product/nc7000/ access on 11.06.2019.

[13] Liu M., Jia Z., Jia D. et al.: Progress in Polymer Science 2014, 39, 1498.

http://dx.doi.org/10.1016/j.progpolymsci.2014.04.004

[14] Pasbakhsh P., Churchaman G.J., Keeling J.L.: Applied Clay Science 2013, 74, 47.

http://dx.doi.org/10.1016/j.clay.2012.06.014

[15] Saeed K., Khan I.: Carbon Letters 2013, 14, 131.

https://doi.org/10.5714/CL.2013.14.3.131

[16] Schmidt A.G., Malwitz M.M.: Current Opinion in Colloid \& Interface Science 2003, 8, 103. https://doi.org/10.1016/S1359-0294(03)00008-6

[17] Kharchenko B.S.B., Douglas J.F., Obrzut J. et al.: Nature Materials 2004, 3, 564.

https://doi.org/10.1038/nmat1183

[18] Moniruzzaman M., Winey K.I.: Macromolecules 2006, 39, 5194. https://oi.org/10.1021/ma060733p

[19] Abbasi S., Carreau P.J., Derdouri A., Moan M.: Rheologica Acta 2009, 48, 943. https://doi.org/10.1122/1.3523628

[20] Sandler J., Shaffer M.S.P., Lam Y.-M. et al.: “CarbonNanofibre-Filled Thermoplastic Composites", MRS 2001 Fall Meeting, Boston MA, USA.

[21] Vishwa P.S, Vimal K.K, Kapur G.S. et al.: Journal of Polymer Research 2016, 23, 43.

https://doi.org/10.1007/s10965-016-0937-1

[22] Yu-Xiao H., Han-Xiong H.: Polymer Engineering and Science 2019, 59, 1585. https://doi.org/10.1002/pen.25156

Received 2 VII 2019. 